DOI: $10.15593 / 2224-9982 / 2020.63 .04$

УДК 629.7.036.34

\author{
С.Е. Пискунов ${ }^{1,2}$, Д.А. Попов ${ }^{1,2}$, Н.А. Самойленко ${ }^{1}$ \\ ${ }^{1}$ Пермский национальный исследовательский политехнический университет, Пермь, Россия \\ ${ }^{2}$ ОДК-Авиадвигатель, Пермь, Россия

\section{ОБЩАЯ КЛАССИФИКАЦИЯ ПОТЕРЬ И ОБЗОР МОДЕЛЕЙ ВТОРИЧНЫХ ТЕЧЕНИЙ В РЕШЕТКАХ ГАЗОВЫХ ТУРБИН}

\begin{abstract}
При проектировании ТРДД особое внимание уделяется повышению экономичности при помощи увеличения показателей эффективности основных узлов. Аэродинамическая эффективность узла турбины зависит от уровня потерь полного давления и кинетической энергии, которые определяются масштабами вторичных течений в межлопаточных каналах решеток турбин. Существует множество исследований и статей на тему вторичных течений, в которых нередко одним и тем же вихревым структурам приписывают различные названия, что говорит о существовании проблемы отсутствия единой модели вторичных течений и рассогласовании названий компонентов вторичных течений при локализации англоязычных моделей на русском языке.

Цель данной обзорной статьи заключается в рассмотрении существующих классификаций потерь и наиболее распространенных моделей вторичных течений в решетках турбин, среди которых модель Ванга, модель Голдштейна и Спорса, модель Шарма и Батлера и пр. На основании рассмотренных источников выделена наиболее полная классификация потерь, сопоставлены друг с другом компоненты вторичных течений из различных моделей, описан механизм их возникновения и дана наиболее полная номенклатура вторичных течений в решетках турбин.

Ключевые слова: турбореактивный двухконтурный двигатель, турбина, турбина высокого давления, аэродинамика, вторичные течения, вихрь, потери полного давления, потери кинетической энергии, рабочая лопатка, сопловой аппарат, терминология вторичных течений, классификация вторичных течений.
\end{abstract}

\author{
S.E. Piskunov ${ }^{1,2}$, D.A. Popov ${ }^{1,2}$, N.A. Samoilenko ${ }^{1}$ \\ ${ }^{1}$ Perm National Research Polytechnic University, Perm, Russian Federation \\ ${ }^{2}$ UEC-Aviadvigatel, Perm, Russian Federation
}

\title{
LOSS CLASSIFICATION AND REVIEW OF SECONDARY FLOW MODELS IN GAS TURBINE CASCADES
}

\begin{abstract}
Much attention is paid to increasing the efficiency of turbofan engines by increasing the efficiency of the main modules. The aerodynamic efficiency of a turbine depends on the level of total pressure and kinetic energy losses, which are determined by the scale of secondary flows in the channels of the turbine cascades. There are many studies and articles on the topic of secondary flows, in which vortex structures are often given incorrect names. The problem lies in the absence of a unified model of secondary flows and mismatch in the names of the components of secondary flows in adaptation of model descriptions from English to Russian.

The purpose of this review article is to consider the existing classifications of losses and the most famous models of secondary flows in turbine cascades, including the Wang model, the Goldstein and Spores model, the Sharma and Butler model, etc. The considered sources of information made it possible to single out the most complete classification of losses, compare with each other the components of secondary flows of various models, describe the mechanism of their occurrence and give the most complete nomenclature of secondary flows in turbine cascades.

Keywords: turbojet engine, turbine, high-pressure turbine, aerodynamics, secondary flows, vortex, total pressure loss, kinetic energy loss, rotor blade, nozzle guide vane, secondary flow terminology, classification of secondary flows.
\end{abstract}

\section{Введение}

Вторичные течения могут значительно влиять на протекание процессов в движущихся жидкостях и газах. Развитые вторичные течения могут локально увеличивать интенсивность конвективного теплообмена $[1,2]$, а также зна- чительно увеличивать потери полного давления и кинетической энергии, поэтому разрабатываются различные мероприятия по снижению потерь, связанных со вторичными течениями [3].

Существует множество исследований на тему вторичных течений, в которых авторам приходится присваивать названия тем или иным 
вихревым структурам. Некоторые из авторов работ, не зная общепринятых моделей вторичных течений или вовсе отказываясь от присваивания имени из-за риска ошибочной идентификации, присваивают им буквенные обозначения, например вихрь А, вихрь Б и тому подобное, но некоторые предпочитают полное название в соответствии с какой-либо моделью, например «канальный вихрь», «ветвь подковообразного вихря со стороны корыта» и т.п.

Зачастую при анализе тех или иных научных работ заметна проблема терминологии и классификации вторичных течений. Помимо того, что вихревые структуры имеют неправильную идентификацию, в различных моделях вторичных течений одинаковые вихри могут иметь различные названия. Также в русскоязычной литературе встречается немало примеров неверной локализации названий составляющих вторичных потерь.

В качестве примера рассогласования можно привести статью [4], в которой изучается влияние вторичных течений на локальные коэффициенты теплоотдачи, а именно увеличение чисел Нуссельта при взаимодействии ветви П-образного вихря с канальным. Термин «П-образный вихрь» не согласуется с наиболее современной моделью вторичных течений [5], в которой используется понятие horseshoe vortex, т.е. подковообразный вихрь. Понятие «П-образный вихрь» используется для описания вторичных течений при обтекании крыла конечной длины в аэродинамике самолета [6], его концы, в отличие от ветвей подковообразного вихря, называются вихревыми усами [7]. Понятие «П-образный вихрь» неприменимо к решеткам турбин исходя из тех соображений, что он лежит в плоскости крыла, а не перпендикулярно ей, как расположен подковообразный вихрь в решетках турбин. В качестве примера рассогласования терминологии можно также привести статью, в которой разрабатываются мероприятия по снижению вторичных потерь в решетках турбин [8]. В данной статье используется термин «входной вихрь» для описания вихря, который, согласно наиболее полной модели [5], называется leading edge corner vortex, т.е. угловой вихрь на входной кромке.
Примеры несоответствия терминологии и локализации названий с терминами, использованными в общепринятых моделях, обусловливают актуальность задачи изучения литературы по вторичным течениям в решетках турбин и описания наиболее полной номенклатуры вторичных течений.

\section{Общая классификация потерь в решетках турбин}

Общая классификация потерь в решетках турбин довольно обширна, и в разных источниках компоненты потерь относят к различным группам. Наиболее полная классификация потерь, описанная в классических учебниках по турбомашинам [9-14], включает в себя следующие потери:

1. Профильные (при отвлечении от концевых потерь и рассмотрении плоских решеток с бесконечно длинными профилями), к которым относятся:

- потери от вихреобразования и трения в пограничном слое и при его срыве;

- потери в вихревых закромочных дорожках и при выравнивании поля скоростей за решеткой;

- потери в скачках уплотнений и при их взаимодействии с пограничным слоем в случае сверхзвуковых скоростей.

2. Концевые (для пространственных решеток конечной длины):

- потери от вторичных течений;

- потери в пограничном слое на торцевых поверхностях;

- потери от перетекания в радиальном зазоре.

3. Дополнительные:

- от смешения основного потока с охлаждающим воздухом;

- паразитного втекания воздуха и неплотностей в газовоздушном тракте;

- трения и вихреобразования в пограничном слое у боковых стенок в осевом зазоре;

- трения диска о газ.

Некоторые авторы $[11,12]$ выделяют в отдельную группу потери, связанные с вращением решетки, которые вызваны следующими причинами: 
1) наличием центробежных сил, в результате чего поток не уравновешен в радиальном направлении и появляются радиальные течения;

2) нестационарностью потока, обусловленной непрерывным изменением взаимного расположения сопловой и рабочей решеток, а также изменением параметров газа в потоке, выходящем из сопловой решетки, как по шагу, так и по высоте решетки.

Существенной особенностью является то, что данная классификация, основная часть которой определена еще в 1950-х гг. (например, работа [10]), остается неизменной и в наше время, за исключением подраздела «Потери от вторичных течений». Если в 1953 г. этот подраздел назывался «Потери от парного вихря» [9], то в современных учебниках по лопаточным машинам этот подраздел включает множество вторичных течений и вихрей, которые обусловливают дополнительные потери $[15,16]$.

\section{Модели вторичных течений}

1. Модель Хафторна [17]. Первая и наиболее простая модель вторичных течений включала в себя всего два вихря (модель представлена на рис. 1).

Passage vortex: в дословном переводе проходной вихрь, локализованное название канальный вихрь. Канальный вихрь возникает в сопловых решетках, в рабочих решетках схожее течение имеет название парного вихря [18].

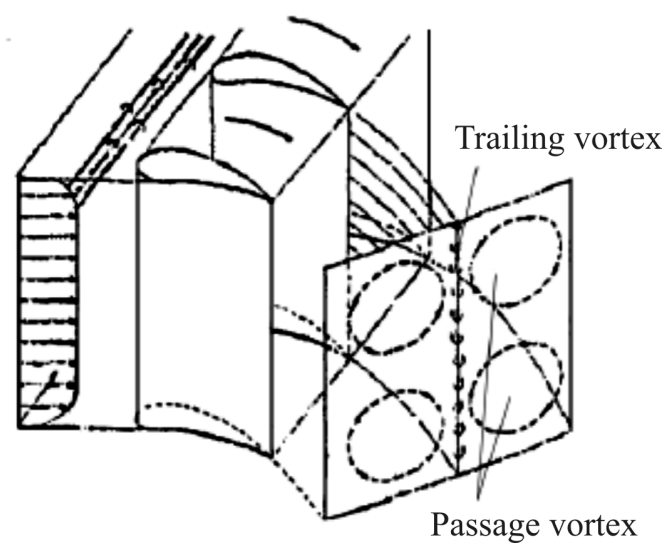

Рис. 1. Модель Хафторна [17]: trailing vortex закромочный вихревой след; passage vortex канальный вихрь
Причиной возникновения канального вихря является сворачивание пограничного слоя на торцевой стенке канала в вихревую структуру при движении от корыта к спине лопатки из-за положительного градиента давления [19]. Вблизи торцевых поверхностей, где наблюдаются большие градиенты параметров потока, более низкая скорость и кинетическая энергия, чем в ядре, в результате чего возникает неуравновешенность между градиентом давления и центростремительным ускорением. Таким образом, поток у торцевых поверхностей прижимается к спинке, вторичные токи вызывают набухание пограничного слоя и его отрыв, в результате чего появляется два вихря, вращающихся в противоположные стороны, направление вращения которых соответствует направлению перетекания [16].

Trailing vortex: в дословном переводе замыкающий вихрь. В русскоязычной литературе упоминается как закромочный вихревой след или закромочная вихревая дорожка [9-14]. Данная вихревая структура упоминалась только в модели Хафторна, в более современных моделях вторичных течений ее нет.

В настоящее время закромочный вихревой след принято относить к профильным потерям.

2. Модель Лэнгстона [20]. Как и модель Хафторна, содержит канальный вихрь (passage vortex). Кроме канального вихря, модель описывает counter vortex, что в дословном переводе означает встречный вихрь.

В более современных моделях [5] и литературе встречный вихрь называется угловым вихрем. Угловой вихрь индуцируется канальным вихрем в месте сопряжения торцевой стенки и спинки лопатки и имеет противоположное направление вращения, из-за чего изначально назывался встречным.

Модель Лэнгстона представлена на рис. 2. Данная модель достаточно точно описывает контуры завихренности на выходе из турбинных решеток, что подтверждено экспериментальными и расчетными исследованиями [19].

3. Модель Шарма и Батлера [21]. В данной модели к канальному вихрю добавляется horseshoe vortex - подковообразный вихрь. Схематично модель представлена на рис. 3 . 
Перо лопатки начинает вносить возмущение в пограничный слой на некотором расстоянии, что приводит к торможению потока и утолщению пограничного слоя по мере приближения к входной кромке. В то же время должно произойти разделение пограничного слоя между спиной и корытом. Давление торможения в пограничном слое на торцевых поверхностях лопатки меньше, чем на входной кромке, в результате чего под воздействием градиента давления поток отделяется в точке $s_{1}$ (рис. 4), называемой saddle point (точка отрыва) [22]. Затем пограничный слой образует обратный ток непосредственно перед передней кромкой и под действием градиента давления отделяется во второй точке $s_{2}$ (см. рис. 4), затем данная вихревая структура разделяется на две ветви:

- Suction side leg horseshoe vortex - ветвь подковообразного вихря со стороны спины: под действием градиента давлений со стороны корыта соседней лопатки прижимается к спине;

- Pressure side leg horseshoe vortex ветвь подковообразного вихря со стороны корыта: под действием градиента давлений начинает смещаться к спине соседней лопатки, пересекая межлопаточный канал.

Согласно модели Шарма и Батлера, ветвь подковообразного вихря со стороны спины оборачивается вокруг канального вихря, а ветвь со стороны корыта сливается с канальным вихрем.

4. Модель Голдштейна и Спорса [23]. В данной модели помимо вышеописанных вихрей добавляется угловой вихрь, физика формирования которого схожа с формированием подковообразного вихря. Угловой вихрь образуется в результате поперечного пересечения потоков на торцевых стенках. Угловой вихрь наиболее сильно заметен в экспериментах со значительным углом поворота потока в решетке [24]. Данная модель представлена на рис. 5.

Suction side corner vortices - угловые вихри на спине.

Pressure side corner vortex - угловой вихрь на корыте.

Pressure side leading edge corner vortex угловой вихрь на входной кромке со стороны корыта.

Suction side leading edge corner vortex угловой вихрь на входной кромке со стороны спины.

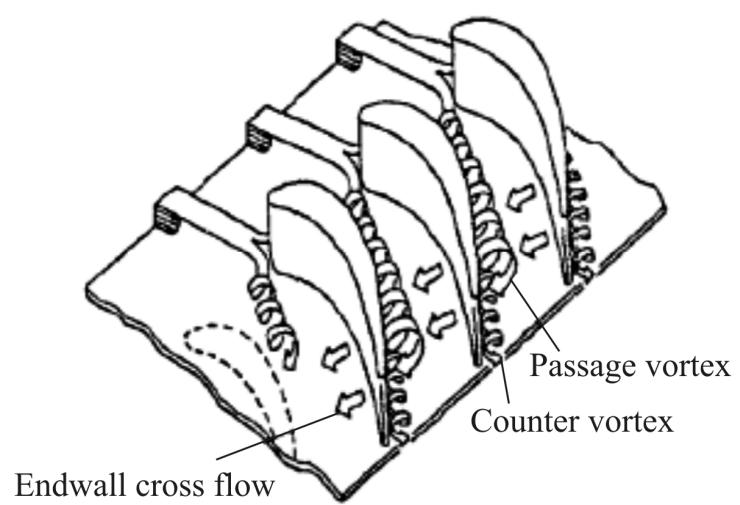

Рис. 2. Модель Лэнгстона [20]: passage vortex закромочный вихревой след; counter vortex встречный вихрь; endwall cross flow - пристеночное поперечное течение в межлопаточном канале

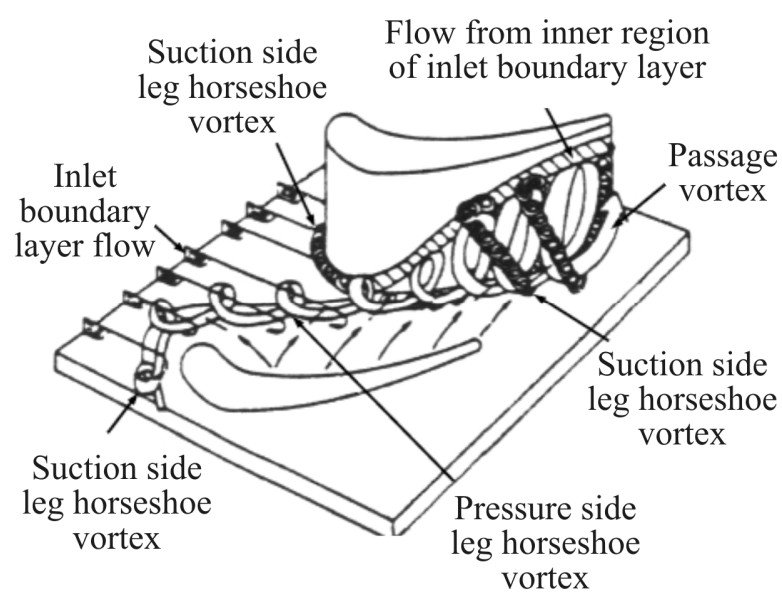

Рис. 3. Модель Шарма и Батлера [21]: suction side leg horseshoe vortex - ветвь подковообразного вихря со стороны спины; pressure side leg horseshoe vortex - ветвь подковообразного вихря co стороны корыта; passage vortex - канальный вихрь; inlet boundary layer flow - входной пограничный поток; flow from inner region of inlet boundary layer - поток из внутренней области входного пограничного слоя

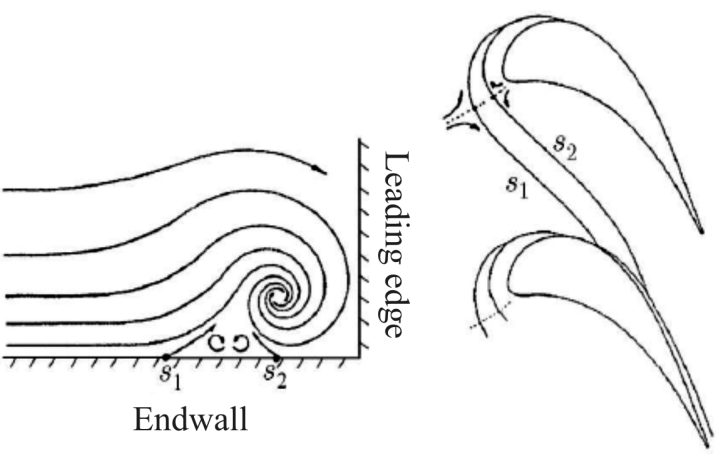

Рис. 4. Точки отрыва $s_{1}$ и $s_{2}$ [22]: endwall - стенка (нижняя); leading edge - входная кромка лопатки 


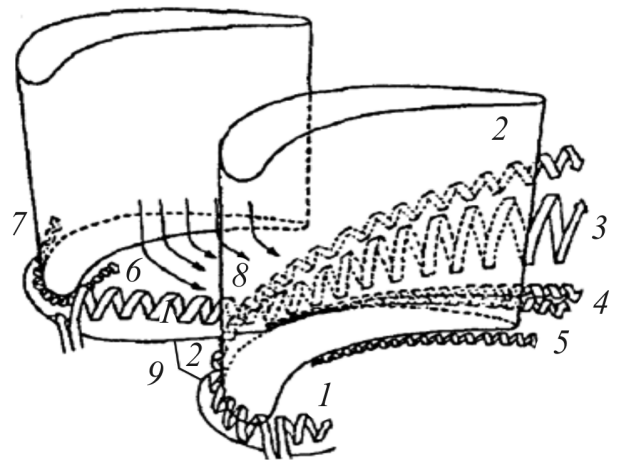

Рис. 5. Модель Голдштейна и Спорса [23]: pressure side horseshoe vortex $(1)$ - подковообразный вихрь со стороны корыта; suction side horseshoe vortex (2) подковообразный вихрь со стороны спины; passage vortex (3) - канальный вихрь; suction side corner vortices (4) - угловые вихри со стороны спины; pressure side corner vortex (5) - угловой вихрь со стороны корыта; pressure side leading edge corner vortex (6) - угловой вихрь на входной кромке со стороны корыта; suction side leading edge corner vortex (7) угловой вихрь на входной кромке со стороны спины; endwall cross flow (8) - пристеночное поперечное течение; separation lines (9) - разделительные линии

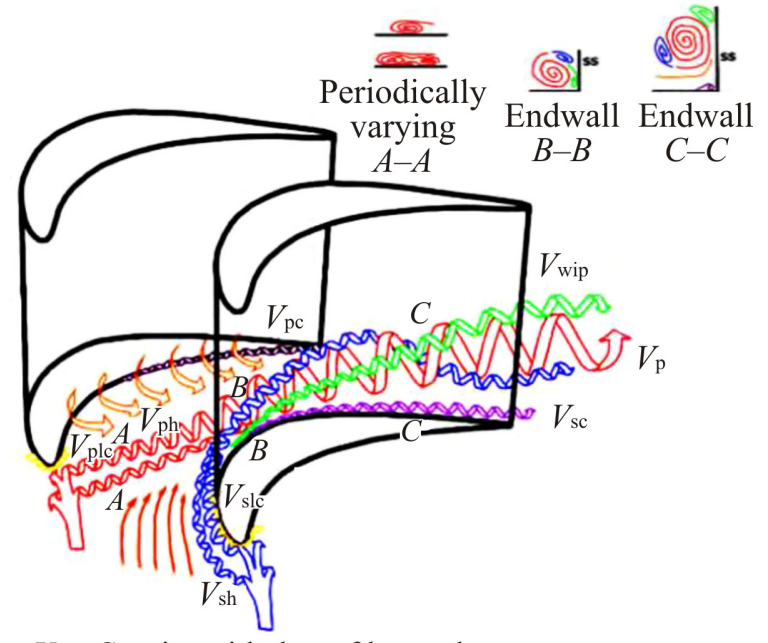

$V_{\text {sh }}$ : Suction side leg of horseshoe vortex

$V_{\mathrm{ph}}$ : Pressure side leg of horseshoe vortex

$V_{\mathrm{p}}$ : Passage vortex

$V_{\text {wip: }}$ Wall vortex induced by the passage vortex

$V_{\text {slc: }}$ Suction side leading edge corner vortex

$V_{\text {plc: }}$ Pressure side leading edge corner vortex

$V_{\text {sc: }}$ Suction side corner vortex

$V_{\mathrm{pc}}$ : Pressure side corner vortex

Рис. 6. Модель Ванга [25]: suction side leg of horseshoe vortex - ветвь подковообразного вихря со стороны спины; pressure side leg of horseshoe vortex - ветвь подковообразного вихря со стороны корыта; passage vortex - канальный вихрь; wall vortex induced by the passage vortex - пристенный вихрь, индуцированный канальным вихрем; suction side leading edge corner vortex - угловой вихрь на входной кромке со стороны спины; pressure side leading edge corner vortex - угловой вихрь на входной кромке со стороны корыта; suction side corner vortex - угловой вихрь на спине; pressure side corner vortex - угловой вихрь на корыте
Угловые вихри представляют собой структуры, образованные в результате разделения основных вторичных потоков в углах между торцевыми поверхностями и спиной (или корытом) лопатки, исходя из этого образовано название «угловой вихрь».

5. Модель Ванга $[5,25]$. Наиболее полная и современная модель вторичных течений по части терминов не отличается от модели Голдштейна и Спорса (п. 4), однако отличается расположение и взаимодействие вихрей. Данная модель используется в большинстве современных исследований по теме вторичных течений, представлена на рис. 6.

В дополнение к модели, описанной в п. 4, данная модель имеет пристенный вихрь wall vortex induced by passage vortex, который индуцирован канальным вихрем. Характер взаимодействия ветви подковообразного вихря со стороны спинки и пристенного вихря с канальным вихрем схож с взаимодействием ветви подковообразного вихря со стороны спинки и канального вихря в модели Шарма и Батлера (сечения $B-B$ и $C-C$ на рис. 6 показывают движение вихрей $V_{\text {wip }}$ и $V_{\text {sh }}$ относительно канального вихря $V_{\text {p }}$ ).

\section{Вихрь утечки через радиальный зазор}

Помимо вихрей, описанных в п. 1-5, для рабочих решеток характерен вихрь утечки через радиальный зазор - tip clearance vortex [26]. Потери энергии, связанные с радиальным зазором, определяются как собственно перетеканием среды через зазор, так и воздействием этого перетекания на другие виды потерь: вторичные, в пограничном слое на кольцевой стенке корпуса и др. [27]. Ввиду этого иногда этот вид потерь оценивают совместно, например, со вторичными, так как перетекание в зазоре над рабочим колесом ТВД может влиять на интенсивность и поведение подковообразного вихря со стороны спинки на периферии рабочей лопатки. Потери от перетекания определяются его интенсивностью и зависят от величины радиального зазора и аэродинамической нагрузки на лопатке, пограничного слоя на корпусе, формы радиального зазора и формы уплотнения торца рабочей лопатки и др. 
Вихрь утечки через радиальный зазор имеет наибольшую интенсивность из всех вышеперечисленных компонентов вторичных течений. Для уменьшения потерь вследствие утечек в радиальном зазоре применяют как активные, так и пассивные методы. Большинство опубликованных в открытых источниках методов являются пассивными и заключаются в геометрическом воздействии на структуру течения в области радиального зазора рабочей решетки ТВД: бандажирование лопаток [28-30], применение истираемых покрытий, применение различных форм уплотнений торцов рабочих лопаток [31] и др. Среди пассивных методов: гидростатический (например, наддув радиального зазора [32]), тепловой, механический и комбинированный.

\section{Заключение}

Примеры несоответствия терминологии и локализации названий терминам, использованным в общепринятых моделях, обусловливают актуальность разработки русскоязычной модели вторичных течений, которая наиболее полно отражала бы структуру вторичных течений и соответствовала бы общепринятым моделям (например, модели Ванга).

В данной статье была описана общая классификация потерь в решетках турбин, основанная на рассмотрении основной отечественной литературы по лопаточным машинам. В то же время на основании статей, содержащих теоретические, экспериментальные и рас- четные данные были рассмотрены основные зарубежные модели вторичных течений. Сопоставлены компоненты вторичных течений в различных моделях, на основании чего предложены русскоязычные названия, которые наиболее полно отражают структуру вторичных течений в решетках турбин.

Таким образом, наиболее полная номенклатура вторичных течений в решетках турбин, согласно общепринятым моделям, включает в себя следующие вторичные течения:

1. Канальный вихрь (passage vortex, в случае сопловых лопаток), или парный вихрь (в случае рабочих лопаток) $-V_{\text {p. }}$.

2. Ветвь подковообразного вихря со стороны корыта (pressure side leg of horseshoe vortex) $-V_{\mathrm{ph}}$.

3. Ветвь подковообразного вихря со стороны спины (suction side leg of horseshoe vortex) $-V_{\text {sh }}$.

4. Пристенный вихрь (wall vortex) $-V_{\text {wip. }}$

5. Угловой вихрь на входной кромке со стороны спины (suction side leading edge corner vortex) $-V_{\text {slc }}$.

6. Угловой вихрь на входной кромке со стороны корыта (pressure side leading edge corner vortex) $-V_{\mathrm{plc}}$.

7. Угловой вихрь со стороны спины (suction side corner vortex) $-V_{\text {sc }}$.

8. Угловой вихрь со стороны корыта (pressure side corner vortex) $-V_{\mathrm{pc}}$.

9. Вихрь утечки через радиальный зазор (tip clearance vortex, для рабочих лопаток) $-V_{\text {tc. }}$.

\section{Библиографический список}

1. Дунайцев А.А., Солонин В.И. Влияние вторичных течений на процессы тепломассообмена в пучках оребренных стержней газоохлаждаемого реактора // Машиностроение и компьютерные технологии. - 2017. - № 3. - С. 65-67.

2. Белова С.Е., Сухов М.С. Влияние интенсивности вторичных течений на газодинамическую эффективность охлаждаемой сопловой лопатки со ступенчатой кромкой // Аэрокосмическая техника, высокие технологии и инновации. - 2018. - Т. 1. - С. 33-35.

3. Вятков В.В., Курдюков А.В., Ремизов А.Е. Выбор способа борьбы с вторичными течениями в лопаточных венцах газовых турбин // Вестник РГАТУ. - 2016. - № 1 (36). - С. 3-4.

4. Кащенко А.А. Локальный теплообмен на торцевых поверхностях решетки профилей соплового аппарата турбины при интенсивных вторичных течениях // Автомобильный транспорт. - 2015. № 36. - C. 48-53.

5. Flow visualization in a linear turbine cascade of high performance turbine blades / H.P. Wang, S.J. Olson, R.J. Goldstein, E.R.G. Eckert // Journal of Turbomachinery. - 1997. - Vol. 119, no. 1. - P. 1-8.

6. Сакорнсин Р., Попов С.А. Улучшение аэродинамических характеристик комбинированного крыла путем добавления треугольного выступа // Труды МАИ. - 2013. - № 65. - С. 29. 
7. Абрамович Г.Н. Прикладная газовая динамика. - 5-е изд., перераб. и доп. - М.: Наука, 1991. Ч. 2. $-304 \mathrm{c}$.

8. Разработка конструктивных мероприятий, обеспечивающих снижение вторичных потерь в венцах газовой турбины / В.В. Вятков, Т.В. Томилина, Д.В. Карелин, С.А. Ковалев // Омский научный вестник. - 2012. - № 2 (110). - С. 157-160.

9. Абианц В.Х. Теория авиационных газовых турбин. - М.: Гос. изд-во оборон. пром-сти, 1953. -217 c.

10. Жирицкий Г.С. Авиационные газовые турбины. - М.: Гос. изд-во оборон. пром-сти, 1950. -517 с.

11. Основы проектирования турбин авиадвигателей / А.В. Деревянко, В.А. Журавлев, В.В. Зикеев [и др.]; под ред. С.З. Копелева. - М.: Машиностроение, 1988. - 328 с.

12. Локай В.И., Максутова М.К., Стрункин В.А. Газовые турбины двигателей летательных аппаратов: Теория, конструкция и расчет: учеб. для втузов. - 3-е изд., перераб. и доп. - М.: Машиностроение, 1991. $-512 \mathrm{c}$.

13. Холщевников К.В. Теория и расчет авиационных лопаточных машин. - М.: Машиностроение, 1970. $-614 \mathrm{c}$.

14. Копелев С.3., Тихонов Н.Д. Расчет турбин авиационных двигателей (Газодинамический расчет. Профилирование лопаток). - М.: Машиностроение, 1974. - 268 с.

15. Белоусов А.Н., Мусаткин Н.Ф., Радько В.М. Теория и расчет авиационных лопаточных машин: учеб. для вузов / Самар. гос. аэрокосм. ун-т. - 2 изд., испр. и доп. - Самара, 2003. - 344 с.

16. Батурин О.В. Конспект лекций по учебной дисциплине «Теория и расчет лопаточных машин» / Самар. гос. аэрокосм. ун-т. - Самара, 2011. - 241 с.

17. Hawthorne W.R. Rotational flow through cascades // The Quartet Journal of Mechanics and Applied Mathematics. - 1955. - Vol. 8, iss. 3. - P. 266-279.

18. Lampart P. Investigation of endwall flows and losses in axial turbines. Part I. Formation of endwall flows and losses // Journal of Theoretical and Applied Mechanics. - January, 2009. - No. 47 (4). - P. 829-853.

19. Самохвалов Н.Ю., Хайрулин В.Т., Тихонов А.С. Верификация расчетных трехмерных моделей образования вторичных вихревых течений в межлопаточных каналах турбин ГТД по данным испытаний тестового профиля Т106 // Вестник Пермского национального исследовательского политехнического университета. Аэрокосмическая техника. - 2017. - № 2 (49). - С. 41-53.

20. Langston L.S. Crossflows in a turbine cascade passage // Journal of Engineering for Power. - 1980. Vol. 102, no. 4. - 80-GT-5. - P. 866-874.

21. Sharma O.P., Butler T.L. Prediction of endwall losses and secondary flows in axial flow turbine cascade // ASME Journal Turbomachinery. - 1987. - No. 109. - P. 229-236.

22. Marchal Ph., Sieverding C.H. Secondary flows within turbomachinery bladings // AGARD-CP-24. 1977. - P. 11.

23. Goldstein R.J., Spores R.A. Turbulent transport on the endwall in the region between adjacent turbine blades // ASME Journal Heat Transfer. - 1988. - No. 110. - P. 862-869.

24. Ingram G.L. Endwall profiling for the reduction of secondary flow in turbines: doctoral thesis / Duhram University. - Duhram, 2003. - 214 p.

25. Lei Qi, Zhengping Zou Unsteady flows in turbines // Noise Control, Reduction and Cancellation Solutions in Engineering. - 2012. - P. 71-98.

26. Patdiwala U.J., Patel H.C., Paresh K. Parmar review on tip clearance flow and secondary flow losses in linear turbine cascade // IOSR Journal of Mechanical and Civil Engineering (IOSR-JMCE). - 2014. - Vol. 11, iss. 3. - P. 33-37.

27. Герасименко В.П., Осипов Е.В., Шелковский М.Ю. Эффекты радиального зазора в турбомашинах // Авиакосмическая техника и технология. - 2004. - № 8 (16). - С. 133-140.

28. Ле Тиен Зыонг, Нестеренко В.Г. Разработка и исследование конструктивных способов повышения КПД в концевых участках рабочих лопаток ТВД авиационных ГТД // Международный научноисследовательский журнал. - 2018. - № 1. - С. 73-84.

29. Особенности вихревой структуры потока в окрестности бандажа с одним гребнем / И.В. Афанасьев, А.В. Грановский, Е.Ю. Марчуков, И.А. Манаев, А.Е. Шунин // ТЕПЛОЭНЕРГЕТИКА. - 2019. № 7. - С. 43-50.

30. Афанасьев И.В., Грановский А.В. Расчетное исследование влияния формы бандажной полки на эффективность ступени газовой турбины // ТЕПЛОЭНЕРГЕТИКА. - 2018. - № 3. - С. 15-22. 
31. Aerothermal optimization of fully cooled turbine blade tips / V. Andreoli, J. Braun, G. Paniagua, Cis De Maesschalck, M. Bloxham, W. Cummings, L. Langford // Journal Of Turbomachinery. - 2019. Vol. 141. - P. 061007-1.

32. Яковлева С.Ю. Повышение КПД ступени газовой турбины при воздушном наддуве радиального зазора рабочего колеса: дис. ... канд. техн. наук / Рыб. гос. авиац. техн. ун-т им. П.А. Соловьева. Рыбинск, 2016. - 138 с.

\section{Reference}

1. Dunaitsev A.A., Solonin V.I. Vliianie vtorichnykh techenii na protsessy teplomassoobmena v puchkakh orebrennykh sterzhnei gazookhlazhdaemogo reaktora [Influence of secondary flows on heat and mass transfer processes in bundles of ribbed rods of a gas-cooled reactor]. Mashinostroenie $i$ komp'iuternye tekhnologii, 2017, no. 3, pp. 65-67.

2. Belova S.E., Sukhov M.S. Vliianie intensivnosti vtorichnykh techenii na gazodinamicheskuiu effektivnost' okhlazhdaemoi soplovoi lopatki so stupenchatoi kromkoi [Influence of the intensity of secondary flows on the gas-dynamic efficiency of a cooled nozzle blade with a stepped edge]. Aerokosmicheskaia tekhnika, vysokie tekhnologii i innovatsii, 2018, vol. 1, pp. 33-35.

3. Viatkov V.V., Kurdiukov A.V., Remizov A.E Vybor sposoba bor'by s vtorichnymi techeniiami v lopatochnykh ventsakh gazovykh turbin [Choosing a method for dealing with secondary flows in the blade rows of gas turbines]. Herald of Ryazan State Agrotechnological University Named after P.A. Kostychev, 2016, no. 1 (36), pp. 3-4.

4. Kashchenko A.A. Lokalnyi teploobmen na tortsevykh poverkhnostiakh reshetki profilei soplovogo apparata turbiny pri intensivnykh vtorichnykh techeniiakh [Local heat transfer on the hub and shroud surfaces of the nozzle guide vane at intense secondary flows]. Avtomobilnyi transport, 2015, no. 36, pp. 48-53.

5. H.P. Wang, S.J. Olson, R.J. Goldstein, E.R.G. Eckert Flow visualization in a linear turbine cascade of high performance turbine blades. Journal of Turbomachinery, 1997, vol. 119, no. 1, pp. 1-8.

6. Sakornsin R., Popov S.A. Uluchshenie aerodinamicheskikh kharakteristik kombinirovannogo kryla putem dobavleniia treugol'nogo vystupa [mproving the aerodynamic performance of the combination wing by adding a triangular lip]. Trudy MAI, 2013, no. 65, 29 p.

7. Abramovich G.N. Prikladnaia gazovaia dinamika chast' 2 [Applied Gas Dynamics Part 2]. Moscow: Nauka, 1991. 304 p.

8. Viatkov V.V., Tomilina T.V., Karelin D.V., Kovalev S.A. Razrabotka konstruktivnykh meropriiatii, obespechivaiushchikh snizhenie vtorichnykh poter' v ventsakh gazovoi turbiny [Development of measures to reduce secondary losses in the vanes of a gas turbine]. Omskii nauchnyi vestnik, 2012, no. 2 (110), pp. $157-160$.

9. Abiants V.Kh. Teoriia Aviatsionnykh gazovykh turbin [Aircraft Gas Turbine Theory]. Moscow: Gosudarstvennoe izdatelstvo oboronnoi promyshlennosti, 1953, 217 p.

10. Zhiritskii G.S. Aviatsionnye gazovye turbiny [Aircraft gas turbines]. Moscow: Gosudarstvennoe izdatelstvo oboronnoi promyshlennosti, 1950, $517 \mathrm{p}$.

11. Derevianko A.V., Zhuravlev V.A., Zikeev V.V. and ect. Osnovy proektirovaniia turbin aviadvigatelei [Aircraft engine turbine design fundamentals]. Moscow: Mashinostroenie, 1988, 328 p.

12. Lokai V.I., Maksutova M.K., Strunkin V.A. Gazovye turbiny dvigatelei letatel'nykh apparatov: Teoriia, konstruktsiia i raschet: Uchebnik dlia vtuzov [Gas turbines of aircraft engines: Theory, design and calculation: Textbook for technical colleges]. Moscow: Mashinostroenie, 1991, 512 p.

13. Kholshchevnikov K.V. Teoriia i raschet aviatsionnykh lopatochnykh mashin [Theory and calculation of aircraft blades]. Moscow: Mashinostroenie, 1970, 614 p.

14. Kopelev S.Z., Tikhonov N.D. Raschet turbin aviatsionnykh dvigatelei. (Gazodinamicheskii raschet. Profilirovanie lopatok) [Calculation of aircraft engine turbines. (Gas-dynamic calculation. Blade profiling)]. Moscow: Mashinostroenie, 1974, 268 p.

15. Belousov A.N., Musatkin N.F., Radko V.M. Teoriia i raschet aviatsionnykh lopatochnykh mashin. Uchebnik dlia vuzov [Theory and calculation of aircraft blades. Textbook for universities]. Samarski gosudarstvennyi aerokosmicheskii universitet. Samara, 2003, 344 p.

16. Baturin O.V. Konspekt lektsii po uchebnoi distsipline «Teoriia i raschet lopatochnykh mashin» [Lecture notes for the academic discipline "Theory and calculation of blade machines"]. Samarskii gosudarstvennyi aerokosmicheskii universitet, 2011, $241 \mathrm{p}$. 
17. Hawthorne W.R. Rotational flow through cascades. The Quartet Journal of Mechanics and Applied Mathematics. 1955, vol. 8, issue 3, pp. 266-279.

18. Lampart P. Investigation of endwall flows and losses in axial turbines. Part I. Formation of endwall flows and losses. Journal of Theoretical and Applied Mechanics. January, 2009, no. 47 (4), pp. 829-853.

19. Samokhvalov N.Yu., Khairulin V.T, Tikhonov A.S. Verifikatsiia raschetnykh trekhmernykh modelei obrazovaniia vtorichnykh vikhrevykh techenii v mezhlopatochnykh kanalakh turbin GTD po dannym ispytanii testovogo profilia T106 [Verification of computational 3D models of secondary flows formation through gas turbine airfoil passages based on T106 profile test]. PNRPU Aerospace Engineering, 2017, no. 2 (49), pp. 41-53.

20. Langston L.S. Crossflows in a Turbine Cascade Passage. Journal of Engineering for Power. 80-GT-5, V. 102, N 4, pp. 866-874, 1980.

21. Sharma O.P., Butler T.L. Prediction of endwall losses and secondary flows in axial flow turbine cascade. ASME J. Turbomachinery, 109, pp. 229-236, 1987.

22. Marchal Ph., Sieverding C.H. Secondary flows within turbomachinery bladings. AGARD-CP-24, $1977,11 \mathrm{p}$.

23. Goldstein R.J., Spores R.A. Turbulent transport on the endwall in the region between adjacent turbine blades. ASME, J. Heat Transfer, 110, pp. 862-869. 1988.

24. Ingram G.L. Endwall profiling for the reduction of secondary flow in turbines. Doctoral thesis, Duhram University, 2003, 214 p.

25. Lei Qi, Zhengping Zou Unsteady Flows in Turbines. Noise Control, Reduction and Cancellation Solutions in Engineering, 2012, pp. 71-98.

26. Patdiwala U.J., Patel H.C., Paresh K. Parmar Review on Tip Clearance Flow and Secondary Flow Losses in Linear Turbine Cascade. IOSR Journal of Mechanical and Civil Engineering (IOSR-JMCE), 2014, vol. 11, issue 3, pp. 33-37.

27. Gerasimenko V.P., Osipov E.V., Shelkovskii M.Iu. Effekty radial'nogo zazora v turbomashinakh [Radial tip clearance effects in turbomachines]. Aviakosmicheskaia tekhnika i tekhnologiia. 2004, no. 8 (16), pp. 133-140.

28. Le Tien Zyong, Nesterenko V.G. Razrabotka i issledovanie konstruktivnykh sposobov povysheniia KPD v kontsevykh uchastkakh rabochikh lopatok TVD aviatsionnykh GTD [Development and research of methods for increasing the efficiency in the tip clearance region of the turbine rotor blades of aviation engine]. Mezhdunarodnyi nauchno-issledovatelskii zhurnal, 2018, no. 1, pp. 73-84.

29. Afanasev I.V., Granovskii A.V., Marchukov E.Iu et al. Osobennosti vikhrevoi struktury potoka v okrestnosti bandazha s odnim grebnem [Features of the vortex flow structure around a one fin shroud]. TEPLOENERGETIKA, 2019, no. 7, pp. 43-50.

30. Afanas'ev I.V., Granovskii A.V. Raschetnoe issledovanie vliianie formy bandazhnoi polki na effektivnost' stupeni gazovoi turbiny [Computational study on the effect of shroud shape on the efficiency of the gas turbine stage]. TEPLOENERGETIKA, 2018, no. 3, pp. 15-22.

31. Aerothermal Optimization of Fully Cooled Turbine Blade Tips. / Andreoli Valeria, Braun James, Paniagua Guillermo, Cis De Maesschalck, Bloxham Matthew, Cummings William, Langford Lawrence. Journal of Turbomachinery, 2019, vol. 141, 061007-1.

32. Iakovleva S.Iu. Povyshenie KPD stupeni gazovoi turbiny pri vozdushnom nadduve radial'nogo zazora rabochego kolesa [Increase in the efficiency of a gas turbine stage with air pressurization of the radial tip clearance]. Ph.D. thesis. Rybinsk, 2016, 138 p.

\section{Об авторах}

Пискунов Станислав Евгеньевич (Пермь, Россия) - аспирант кафедры «Авиационные двигатели» ФГБОУ ВО ПНИПУ (614990, г. Пермь, Комсомольский пр., д. 29); инженер-конструктор - расчетчик отдела расчетно-экспериментальных работ по турбинам АО «ОДК-Авиадвигатель» (614990, г. Пермь, Комсомольский пр., д. 93, e-mail: piskunov-se@avid.ru).

Попов Денис Андреевич (Пермь, Россия) - аспирант кафедры «Авиационные двигатели» ФГБОУ ВО ПНИПУ (614990, г. Пермь, Комсомольский пр., д. 29); инженер-конструктор - расчетчик отдела расчетно-экспериментальных работ по турбинам АО «ОДК-Авиадвигатель» (614990, г. Пермь, Комсомольский пр., д. 93, e-mail: popov-da@avid.ru). 
Самойленко Никита Андреевич (Пермь, Россия) - студент кафедры «Авиационные двигатели» ФГБОУ ВО ПНИПУ (614990, г. Пермь, Комсомольский пр., д. 29, e-mail: nikita5am@yandex.ru).

\section{About the authors}

Stanislav E. Piskunov (Perm, Russian Federation) - PhD Student of Aircraft Engines Department, Perm National Research Polytechnic University (29, Komsomolsky av., Perm, 614990, Russian Federation); Design and Analysis Engineer of Turbine Analysis and Experiment Department, JSC "UEC-Aviadvigatel" (93, Komsomolsky av., Perm, 614990, Russian Federation, e-mail: piskunov-se@avid.ru).

Denis A. Popov (Perm, Russian Federation) - PhD Student of Aircraft Engines Department, Perm National Research Polytechnic University (29, Komsomolsky av., Perm, 614990, Russian Federation); Design and Analysis Engineer of Turbine Analysis and Experiment Department, JSC “UEC-Aviadvigatel” (93, Komsomolsky av., Perm, 614990, Russian Federation, e-mail: popov-da@avid.ru).

Nikita A. Samoylenko (Perm, Russian Federation) - Student of Aircraft Engines Department, Perm National Research Polytechnic University (29, Komsomolsky av., Perm, 614990, Russian Federation, e-mail: nikita5am@yandex.ru).

Получено 26.10.2020 